\title{
Electrochemical Behavior of Malachite Green in Aqueous Solutions of Ionic Surfactants
}

\author{
Mohammad Mijanur Rahman, ${ }^{1}$ M. Yousuf A. Mollah, ${ }^{1}$ \\ M. Muhibur Rahman, ${ }^{2}$ and Md. Abu Bin Hasan Susan ${ }^{1}$ \\ ${ }^{1}$ Department of Chemistry, University of Dhaka, Dhaka 1000, Bangladesh \\ ${ }^{2}$ University Grants Commission of Bangladesh, Agargaon, Dhaka 1207, Bangladesh \\ Correspondence should be addressed to Md. Abu Bin Hasan Susan; susan@du.ac.bd
}

Received 22 July 2013; Accepted 24 August 2013

Academic Editors: H. Karimi-Maleh and R. Kizek

Copyright (C) 2013 Mohammad Mijanur Rahman et al. This is an open access article distributed under the Creative Commons Attribution License, which permits unrestricted use, distribution, and reproduction in any medium, provided the original work is properly cited.

Electrochemical behavior of malachite green (MG) oxalate in aqueous solution was studied in the presence of a cationic surfactant, cetyltrimethylammonium bromide (CTAB), and an anionic surfactant, sodium dodecyl sulfate (SDS) at a glassy carbon electrode using cyclic voltammetry. The electrochemical oxidation of MG has been characterized as an electrochemically irreversible diffusion-controlled process. Oxidative peak current sharply decreased with increasing SDS concentration, while a slight increase with increasing [CTAB] was apparent. The apparent diffusion coefficient, the surface reaction rate constant, and the electron transfer coefficient of MG clearly show correlation of the electrochemical behavior with the dissolved states of the surfactants. Electrochemical observations together with spectrophotometric results at varying surfactant concentrations provide evidence of interaction of MG with the surfactants to varying extent depending on the type of the surfactant and the concentration.

\section{Introduction}

Triphenylmethane (TPM) dyes, an important class of synthetic organic compounds, have been a promising material for diverse applications, which inter alia include the following: as fungicides in aquaculture, as parasiticides in pharmaceuticals, as dye materials in industry, and as redox mediators, bioprobes, and $\mathrm{pH}$ indicators in both fundamental and applied sciences [1-6]. A proper understanding and development of fundamental knowledge base of physicochemical properties of TPM dyes have therefore attracted significant attention. Techniques so far employed for this are polarography [7], conductometry [8,9], potentiometry [10], spectrophotometry [11, 12], electrochemical methods [13], membrane selective electrode [14], and so on. Dyes of TPM backbones such as malachite green (MG), crystal violet [15], ethyl violet [16], and victoria blue B [17] are electrochemically active, and recent surge of interest has been the exploration of the redox behavior of such dyes. Among the TPM dyes the prospect of MG (chemical structure shown in Scheme 1) for versatile applications [1] prompted many researchers to study the electrochemical behavior of MG for development of electrochemically switchable devices. The electrochemical oxidation of MG occurs at $\mathrm{N}$-containing lone-pair electron, and the reduction process is due to reduction of oxidized tertiary amino group of MG $[2,10]$. In acidic aqueous solutions, the anodic oxidation of MG leads to the formation of the oxidized form of $N, N, N^{\prime}, N^{\prime}$-tetramethylbenzidine (TMB) ([1, $1^{\prime}$-biphenyl $]-4,4^{\prime}$-diamine), that is, TMBOx whereas the oxidation of the dye in liquid sulphur dioxide is quite different from the observation in acidic aqueous medium $[18,19]$. The electrochemical behavior of MG also exhibits strong $\mathrm{pH}$ dependence and the oxidation of protonated, and hydrated forms of MG is an electrochemically irreversible, diffusion-controlled two-electron transfer process $[18,20]$. The MG dye in surfactant-based organized media may be even more interesting and help to develop electrochemically switchable molecular devices; however, solution behavior and electrochemistry at the interfaces for the dye in such systems are yet to be systematically studied. 


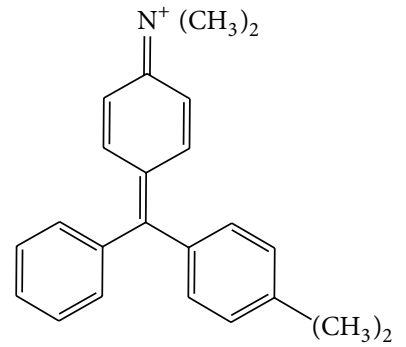

SCHEme 1: Chemical structure of $\mathrm{MG}^{+}$.

There are numerous reports on the study of the electrochemical behavior of electroactive species in surfactant-based organized media in literature. The electrochemical behavior of redox-active surfactants containing different electroactive groups has been found to be controllable by changing the concentration of surfactants $[21,22]$. Susan and coworkers [23-25] reported the solution behaviors of redox-active amphiphiles linked with an anthraquinone group and correlated the electrochemical behavior of anthraquinone with the dissolved states of the nonionic surfactant. Haque et al. $[26,27]$ studied the electrochemical responses of sodium salt of anthraquinone-2-sulphonic acid (AQS) on the dissolved states of the surfactant, cetyltrimethylammonium bromide $(\mathrm{CTAB})$, and found that the current-potential behavior is profoundly influenced by the concentration of the surfactant and redox state of anthraquinone. Similar observation was reported for electrochemical behavior of AQS in a nonionic surfactant, Triton X-100 [28]. Pedraza et al. [29] showed that opposite charges of dye and surfactant can form dyesurfactant complex in solution. The behaviors of TPM dyes in different aqueous anionic surfactant solutions were studied by spectral measurements, and it was reported that dyesurfactant ion pairs form at the surfactant concentrations well below their critical micelle concentration (CMC) [30]. Huang et al. [31] also showed that the negatively-charged sodium dodecyl benzene sulphonate interacts with positively charged MG and can accumulate onto carbon paste electrode surface by electrostatic interaction. On the other hand, the cationic surfactant, cetylpyridinium bromide (CPB) makes the oxidation of MG more difficult due to adsorption of CPB on the electrode surface [32]. In similarly charged dye-micelle systems, the electrostatic repulsion can be overcome by strong hydrophobic interactions [33-35].

MG has two amino groups in its structure and is highly soluble in water. Three phenyl rings in the structure offer MG strong hydrophobic characteristics, while the positive charge of the dye provides the scope of interaction to varying extent with cationic and anionic surfactants to different extent both in the monomeric and micellized states. These make MG an intriguing probe for electrochemical studies. With a view to understanding the aqueous electrochemistry of MG and its interactions with ionic surfactants, we therefore investigated the cyclic voltammetric behavior of MG at a glassy carbon electrode (GCE) surface in aqueous solution and in presence of ionic surfactants of CTAB and sodium dodecyl sulfate
(SDS) and compared electrochemical responses in different media to correlate with the dissolved states of the surfactants.

\section{Experimental}

2.1. Materials. Malachite green oxalate $\left(\left[\left(\mathrm{C}_{23} \mathrm{H}_{25} \mathrm{~N}_{2}\right)\right.\right.$ $\left.\cdot\left(\mathrm{C}_{2} \mathrm{HO}_{4}\right)\right]_{2} \cdot \mathrm{C}_{2} \mathrm{H}_{2} \mathrm{O}_{4}, N, N, N^{\prime}, N^{\prime}$-tetramethyl-4, $4^{\prime}$-diaminotriphenylcarbenium oxalate) from TCI, Tokyo, Japan, cetyltrimethylammonium bromide (CTAB) and sodium dodecyl sulfate (SDS) from Merck, and sulfuric acid $\left(\mathrm{H}_{2} \mathrm{SO}_{4}\right)$, lead dioxide $\left(\mathrm{PbO}_{2}\right)$, perchloric acid $\left(\mathrm{HClO}_{4}\right)$, potassium chloride $(\mathrm{KCl})$, hydrochloric acid $(\mathrm{HCl})$, and sodium hydroxide $(\mathrm{NaOH})$ from $\mathrm{BDH}$ were used as received without further purifications. Solutions were prepared with deionized water (conductivity: $0.055 \mu \mathrm{S} \mathrm{cm}^{-1}$ at $25^{\circ} \mathrm{C}$ ) from HPLC grade water purification systems (BOECO, Germany). A sonicator (LU-2 Ultrasonic cleaner, USA) was used to clean electrodes and to prepare stock solutions.

2.2. Measurements. Spectrophotometric measurements were made with a double-beam Shimadzu UV-visible spectrophotometer (model UV-1650 PC) by using quartz cells with $1 \mathrm{~cm}$ path length. Cyclic voltammetric measurements were performed with a computer-controlled electrochemical analyzer (CHI 600D; CH Instruments, USA). A single compartment three-electrode cell containing a GCE with geometric area of $0.071 \mathrm{~cm}^{2}$ as the working electrode, a silver-silver chloride $(\mathrm{Ag} / \mathrm{AgCl})$ electrode $(1.00 \mathrm{M} \mathrm{KCl})$ as the reference electrode, and a platinum coil as the counter electrode were used for electrochemical measurements. The surface of the working electrode was mirror polished with $0.05 \mu \mathrm{m}$ alumina (Buehler) before each run. The electrochemical measurements were carried out using $0.10 \mathrm{M} \mathrm{KCl}$ aqueous solution as the supporting electrolyte. A pH meter (HM-26 S, TOA electronics Ltd., Japan) was used for measurements of $\mathrm{pH}$ values of solutions. The electrochemical and spectral measurements were conducted at constant room temperature $\left(25 \pm 0.5^{\circ} \mathrm{C}\right)$.

\section{Results and Discussion}

3.1. Dye-Surfactant Interaction of $M G$ with $C T A B$ and SDS in Aqueous Solution. The visible spectrum of MG in aqueous solution shows a broad band at the absorption maximum of $617.5 \mathrm{~nm}\left(\varepsilon=1.00 \times 10^{5} \mathrm{M}^{-1} \mathrm{~cm}^{-1}\right)$. The absorption spectra of $\mathrm{MG}$ in aqueous solutions with change in concentration of CTAB and SDS were measured, and spectral analyses were made to correlate dye-surfactant interaction with the dissolved states of the surfactants.

Figure 1(a) represents the visible spectra of $1.0 \times 10^{-6} \mathrm{M}$ MG in $1.0 \times 10^{-4} \mathrm{M}$ aqueous solution of $\mathrm{KCl}$ at $25 \pm 0.1^{\circ} \mathrm{C}$ for CTAB. The absorbance at the $\lambda_{\text {max }}$, that is, $617.5 \mathrm{~nm}$ as a function of $[\mathrm{CTAB}]$ profile is also presented in Figure 1(b). The $\lambda_{\max }$ did not show any appreciable change with increasing concentration of CTAB. The absorbance at the $\lambda_{\text {max }}$, on the other hand, increases with increasing [CTAB] up to a concentration of $0.25 \times 10^{-3} \mathrm{M}$ after which absorbance apparently decreases with further increase in [CTAB] (Figure 1(b)).

Both MG and CTAB are positively charged, and therefore at low concentrations of CTAB, electrostatic repulsion 


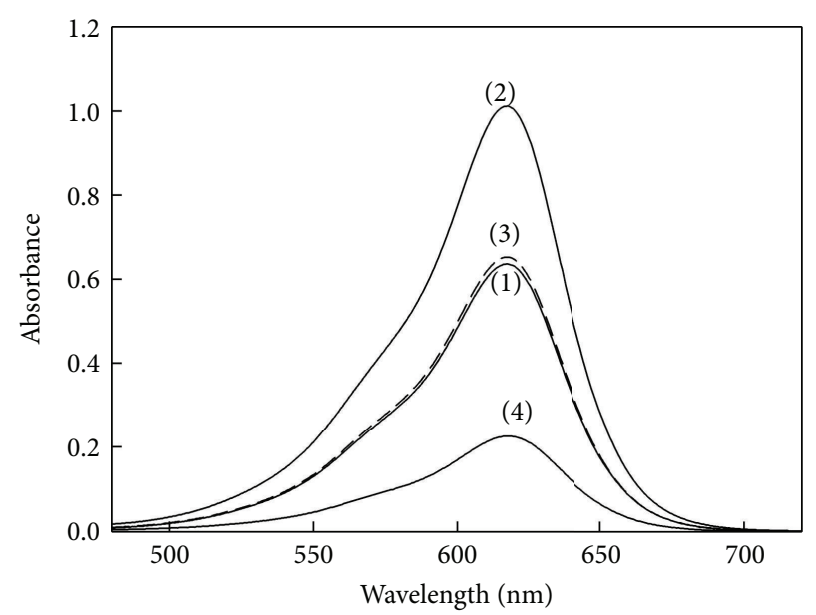

$[\mathrm{CTAB}] \times 10^{3} \mathrm{M}=$

(1) 0

(2) 0.25
(3) 1.00

(4) 4.50

(a)

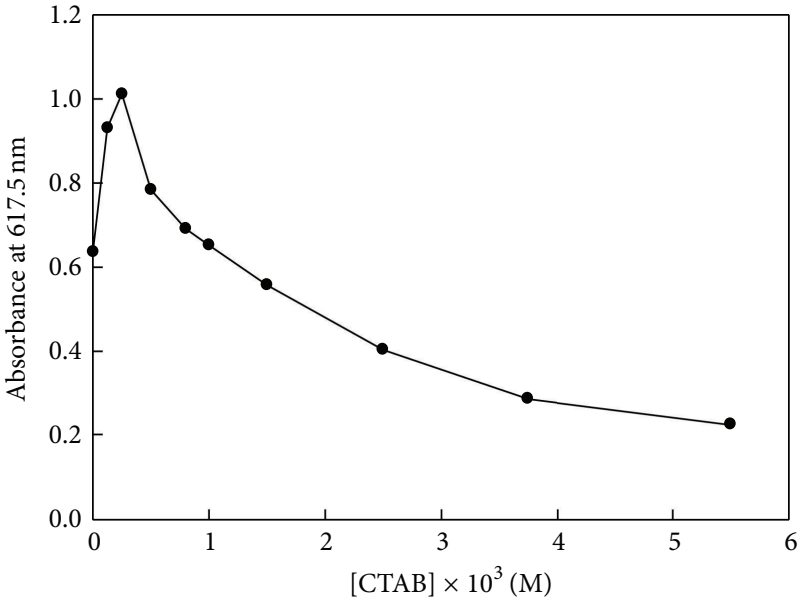

(b)

Figure 1: (a) Absorption spectra of $1.0 \times 10^{-6} \mathrm{M} \mathrm{MG}$ in $0.10 \mathrm{M}$ aqueous solution of $\mathrm{KCl}$ in the presence of CTAB at various concentrations; (b) absorbance at $617.5 \mathrm{~nm}$ versus [CTAB].

between MG and CTAB becomes dominant and free MG species contribute more to the absorption to show an increase in absorbance with increasing [CTAB]. However, at high concentrations of CTAB, self association results in the formation of thermodynamically stable aggregates of colloidal dimension, that is, micelles and the hydrophobicity of MG favors solubilization in the core of micelles to result in a consequent decrease in the absorbance.

Figure 2(a) shows the absorption spectra of $1.0 \times 10^{-6} \mathrm{M}$ MG in $0.10 \mathrm{M}$ aqueous solution of $\mathrm{KCl}$ in the presence of SDS of varying concentrations, while Figure 2(b) shows the absorbance at $617.5 \mathrm{~nm}$ as a function of [SDS]. The addition of SDS to aqueous solution of MG causes a shift in the position of $\lambda_{\max }$ towards longer wavelength. The absorbance at $617.5 \mathrm{~nm}$ was also found to decrease with increasing SDS concentration up to $0.6 \times 10^{-3} \mathrm{M}$. These are indicative of binding of monomeric SDS with the carbocationic dye, MG. At concentrations of SDS above $0.70 \times 10^{-3} \mathrm{M}$, a sharp increase in absorbance is apparent, which levels off above [SDS] $=7.5 \times$ $10^{-3} \mathrm{M}$. In the submicellar range, the monomeric surfactant tends to aggregate but compete with the strong interaction of positively charged MG and negatively charged SDS, and finally MG species are solubilized by SDS micelles.

Interestingly, for $2.0 \times 10^{-3} \mathrm{M}$ SDS, a new weak band due possibly to the formation of dimer of MG appears at $\lambda_{\max }=$ $584.0 \mathrm{~nm}$ (Figure 2(a)) for MG solution and the shoulder diminishes at $6.0 \times 10^{-3} \mathrm{M}$. The $\lambda_{\max }$ exhibits a bathochromic shift from $617.5 \mathrm{~nm}$ to ca. $626.0 \mathrm{~nm}$ for addition of SDS in the MG to attain a constant value from $7.5 \times 10^{-3} \mathrm{M}$ (inset of Figure 2(a)). This further emphasizes that dye-surfactant interaction plays a key role for change in spectrophotometric behavior, and when micellization occurs, the solubilization behavior outweighs the dye-surfactant interactions.
The $\lambda_{\max }$ versus [surfactant] and absorbance-[surfactant] profiles greatly differed to reflect the differences in interaction of MG with CTAB and SDS. Varying electrostatic and hydrophobic interactions of the positively charged MG with the positively charged CTAB and negatively charged SDS in monomeric and micellized states are interesting. In the subsequent sections, the difference will be correlated with change in electrochemical behavior of $\mathrm{MG}$ in aqueous solutions of CTAB and SDS.

3.2. Electrochemical Behavior of $M G$ in Aqueous Medium in the Absence of Surfactants. Cyclic voltammetric behavior of MG in $\mathrm{KCl}$ aqueous solution at GCE was investigated at potential sweeps from 0.10 to $0.80 \mathrm{~V}$. The electrochemical responses have been found to fairly depend on the concentrations of MG (Figure 3). At $5.0 \times 10^{-4} \mathrm{M} \mathrm{MG}$ in $\mathrm{KCl}$ aqueous solution, and the cyclic voltammogram at the scan rate of $0.01 \mathrm{~V} \mathrm{~s}^{-1}$ shows one anodic peak at $0.63 \mathrm{~V}$ in the positive scan and one reduction peak at $0.37 \mathrm{~V}$ on the reverse scan (Part (A) of Figure 3). The shapes of the cyclic voltammograms agree with those reported by literatures $[13,17,18]$. When anodic potential is applied, the electrochemical oxidation of TPM dyes has been reported to lead to the formation of TMBOx resulting from the ejection of an integral unit of the central carbon attached to a phenyl group followed by intramolecular coupling of two phenyl fragments [18]. In the reverse scan, TMBOx is reduced to its final product, TMB [18]. With decreasing concentration of MG, anodic peak current decreases with a shift in peak potential towards less positive values (Parts (B) and (C) of Figure 3). The observed oxidation peak currents were found to increase linearly with increasing concentration of MG at the concentration range of $1.0 \times 10^{-6}$ to $5.0 \times 10^{-4} \mathrm{M}$ in aqueous solution of $\mathrm{KCl}$. Moreover, at a 


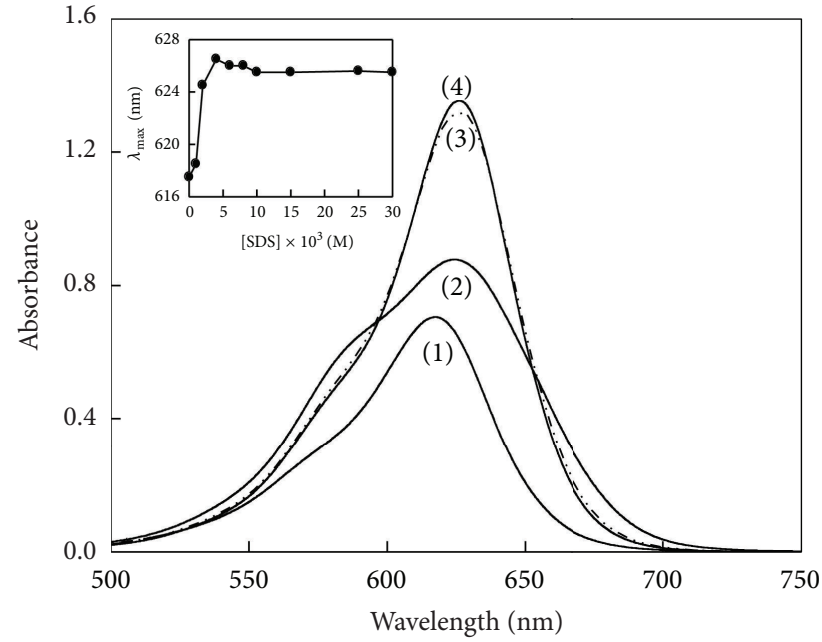

$[\mathrm{SDS}] \times 10^{3} \mathrm{M}=$

(1) 0

(2) 2.0
(3) 8.0

(4) 30.0

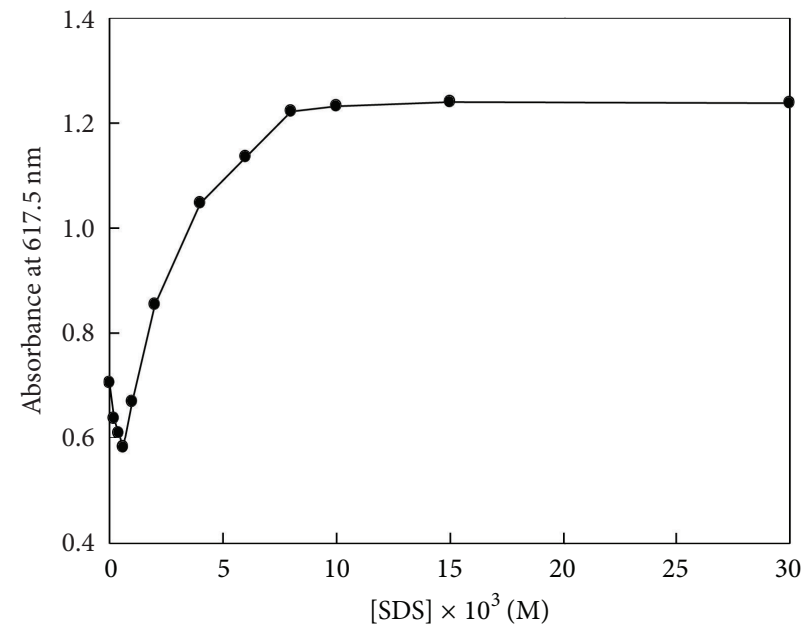

(a)

(b)

Figure 2: (a) Absorption spectra of $1.0 \times 10^{-6} \mathrm{M}$ MG in $0.10 \mathrm{M}$ aqueous solution of $\mathrm{KCl}$ in the presence of SDS at various concentrations. Inset shows plot of [SDS] versus $\lambda_{\max }$. (b) Absorbance at $617.5 \mathrm{~nm}$ versus [SDS].

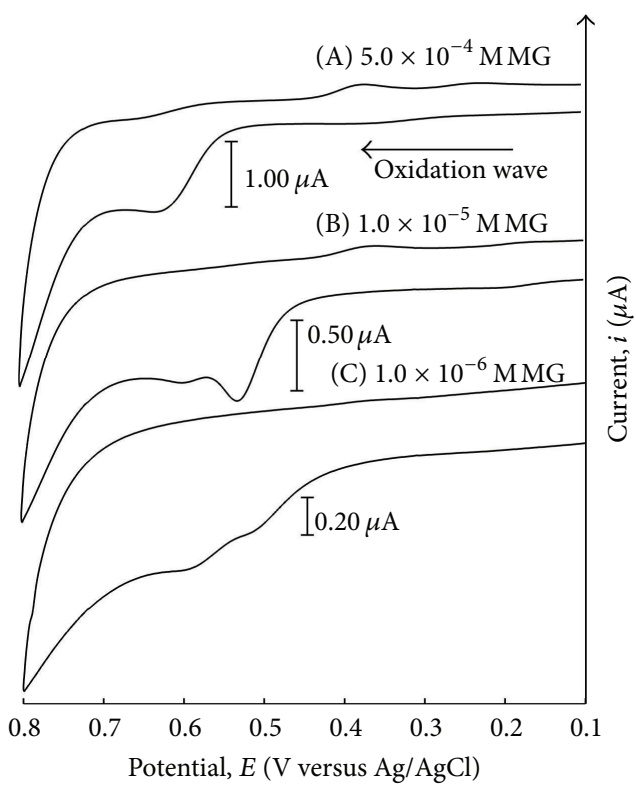

FIGURE 3: Dependence of cyclic voltammograms on concentration of MG in aqueous solution of $\mathrm{KCl}$ at the scan rate of $0.01 \mathrm{~V} \mathrm{~s}^{-1}$.

very low concentration of MG $\left(1.0 \times 10^{-6} \mathrm{M}\right)$, the cathodic peak cannot be distinguished (Part (C) of Figure 3).

Cyclic voltammetric measurements of $5.0 \times 10^{-4} \mathrm{M} \mathrm{MG}$ in $0.10 \mathrm{M} \mathrm{KCl}$ aqueous solution were also carried out at GCE at a scan rate ranging from 0.01 to $0.5 \mathrm{~V} \mathrm{~s}^{-1}$ (Figure 4). In the first scan, MG leads to the formation of TMBOx and is reduced to TMB. In the subsequent scan (by polishing the
GCE surface before each run), the anodic and cathodic peak currents increase with increasing scan rate (Figure 4(a)).

If voltammetric experiments are carried out under identical scan rate without polishing the GCE for subsequent scan, a new oxidation peak (O2) appears at a potential less positive than the first anodic peak O1 (Figure 4(b)). The $\mathrm{O} 2$ is the oxidation wave of the reductive peak (R1) and corresponds to the redox couple, TMBOx/TMB [18], where TMBOx refers to the oxidized form of TMB (Scheme 2). The cathodic peak current increases from the subsequent scans due to the diffusion of reducible species, TMBOx, to the electrode interface $[18,36]$. For successive scans, the O1 decreases cycle by cycle with increase of peak current of TMBOx/TMB redox couple (figure not shown). Chen et al. [10] inferred that the growth of MG film on bare GCE due to electropolymerization may be responsible for this change.

3.3. Electrochemical Behavior of $M G$ in Presence of CTAB and SDS in Aqueous Solution. Electrochemical behavior of MG at a GCE with $\mathrm{KCl}$ aqueous solution as the supporting electrolyte was studied in the presence of ionic surfactants, $\mathrm{CTAB}$, and SDS of varying concentrations (Figure 5). The anodic oxidation peak potential and peak current of MG vary in aqueous solutions of CTAB and SDS (Figures 5(a) and $5(\mathrm{~b}))$. Below the concentrations of $1.00 \times 10^{-3} \mathrm{M}$, the anodic peak current corresponding to $\mathrm{O} 1\left(i_{\mathrm{pa}}^{1}\right)$ increases with increasing $[\mathrm{CTAB}]$ and the anodic peak potential $\left(E_{\mathrm{pa}}^{1}\right)$ shifts to more positive values. At concentrations above $1.00 \times 10^{-3} \mathrm{M}$ of CTAB, the $E_{\mathrm{pa}}^{1}$ is almost constant while a slight increase of $i_{\mathrm{pa}}^{1}$ is apparent (Figure 5(a)). MG is a cationic dye and CTAB is a cationic surfactant; therefore, due to electrostatic repulsion, hydrophobic interaction prevails. As the concentration of 


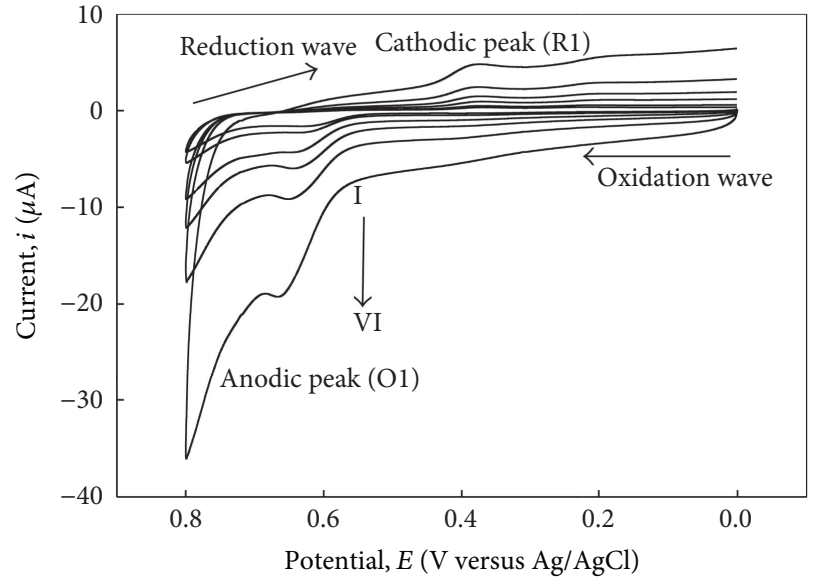

(a)

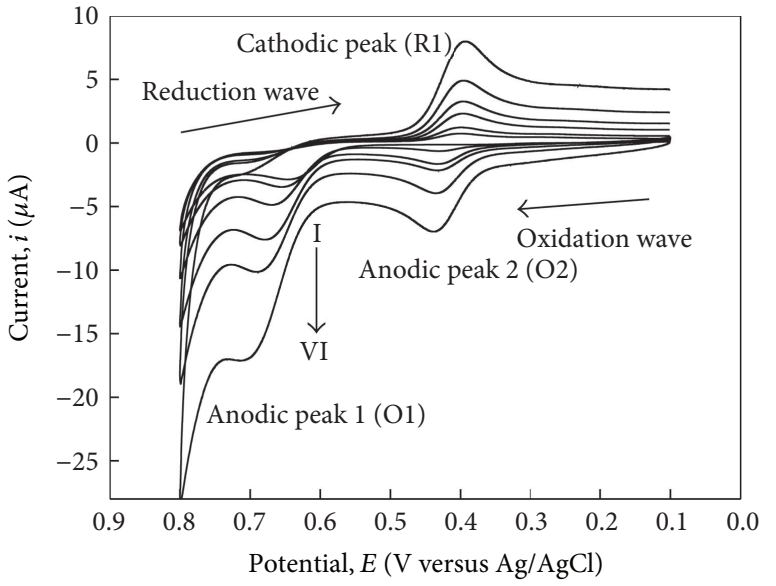

(b)

FIGURE 4: Cyclic voltammograms of $5.0 \times 10^{-4} \mathrm{M} \mathrm{MG}$ in aqueous solution at different scan rates (I: 0.01 and VI: $0.50 \mathrm{Vs}{ }^{-1}$ ): (a) the GCE was polished prior to each measurements; (b) the subsequent measurements without further polishing of GCE.

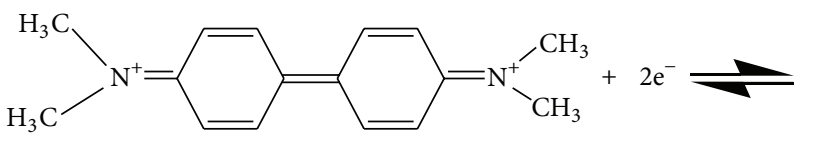

TMBOx<smiles>CN(C)c1ccc(-c2ccc(N(C)C)cc2)cc1</smiles>

TMB

Scheme 2: Redox reaction of TMBOx.

CTAB is further increased, electrostatic repulsion between the micellar head groups and positively charged MG increases discouraging further solubilization of $\mathrm{MG}$ in the core of micelle.

SDS affects both $E_{\mathrm{pa}}^{1}$ and $i_{\mathrm{pa}}^{1}$ of the MG in aqueous solutions. At concentrations below $1.00 \times 10^{-3} \mathrm{M}$, the $i_{\mathrm{pa}}^{1}$ decreases with increasing SDS and the $E_{\mathrm{pa}}^{1}$ shifts to less positive values. At $1.00 \times 10^{-3} \mathrm{M}$, the $E_{\mathrm{pa}}^{1}$ shifts slightly to higher potential. With further addition of SDS, the $E_{\mathrm{pa}}^{1}$ shifts to less positive values. The $i_{\mathrm{pa}}^{1}$ reaches almost a constant value as the concentration of SDS reaches $4.0 \times 10^{-3} \mathrm{M}$. (inset of Figure 5(b)). This may be ascribed to the fact that at very low concentrations of SDS, MG interacts with monomeric SDS. With increase in SDS concentration, $i_{\mathrm{pa}}^{1}$ decreases. This may be due to slower diffusion of MG incorporated in micelle to the electrode interface. The dye-monomer surfactant interaction is supported by the changes in absorbance and wavelength corresponding to the absorption maximum $\left(\lambda_{\max }\right)$ in the visible spectra with change in SDS concentration for a fixed [MG] (Section 3.1).

The anodic peak current, $i_{\mathrm{pa}}^{1}$, versus [surfactant] profiles may also be used for the electrochemical estimation of the $\mathrm{CMC}$ values of CTAB and SDS with $5 \times 10^{-4} \mathrm{M} M \mathrm{MG}$ in $0.10 \mathrm{M}$ aqueous solution of $\mathrm{KCl}$. The $\mathrm{CMC}$ values as apparent from inset of Figures 5(a) and 5(b) are $1.00 \times 10^{-3}$ and $4.00 \times 10^{-3} \mathrm{M}$, respectively for $\mathrm{CTAB}$ and SDS under the experimental conditions used. The values are different from those reported in the literature especially using specific conductance and tensiometric measurements. This is not surprising. The difference in the technique of measurements gives rise to difference in CMC. Takeoka et al. [22] reported the CMC value of a ferrocenyl surfactant from the surface tension measurements to be $0.012 \mathrm{mM}$, which is estimated as $0.089 \mathrm{mM}$ from electrochemical measurements. Similar observations are also reported for an anthraquinonyl surfactant [25].

The cyclic voltammograms of MG indicate that the anodic and cathodic peak currents increase as the scan rate is increased. The plot of logarithm of peak current versus logarithm of scan rate allows us to diagnose the electrochemical process in aqueous media (not shown in the figure). The theoretical slope for a diffusion-controlled voltammogram is 0.5 and for ideal adsorption it is 1 [37]. The value of the slope of the plot was in range 0.43 to 0.51 for the peaks $\mathrm{O} 1$ and $\mathrm{R} 1$ while the value ranged from 0.60 to 0.74 for peak O2. This indicates that the peaks $\mathrm{O} 1$ and $\mathrm{R} 1$ are diffusion-controlled, but the anodic peak of $\mathrm{O} 2$, whether in absence or in presence of surfactants, has influences from adsorbed species on the overall electrochemical process.

Figure 6 depicts the effect of CTAB and SDS on the half wave potentials $\left(E_{1 / 2}\right.$, taken as the average of the potential of the second anodic peak, $\mathrm{O} 2\left(E_{\mathrm{pa}}^{2}\right)$ and the cathodic peak, $\mathrm{R} 1\left(E_{\mathrm{pc}}\right)$ for the subsequent cycles) of TMBOx/TMB redox couple. No significant changes in potentials were observed up to concentration of $2.5 \times 10^{-3} \mathrm{M}$ SDS, after which the peak potential showed a sharp fall. This may be due to strong dyesurfactant interactions. On the other hand, $E_{1 / 2}$ shows only a 


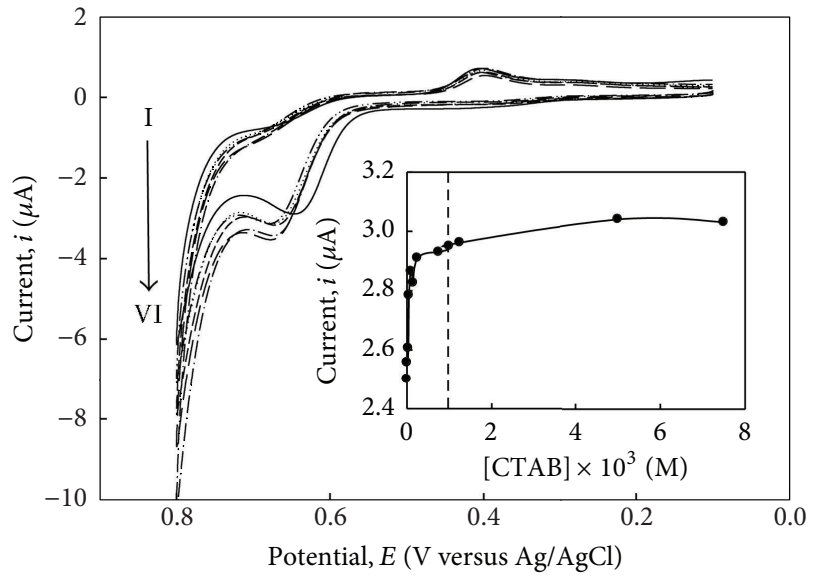

(a)

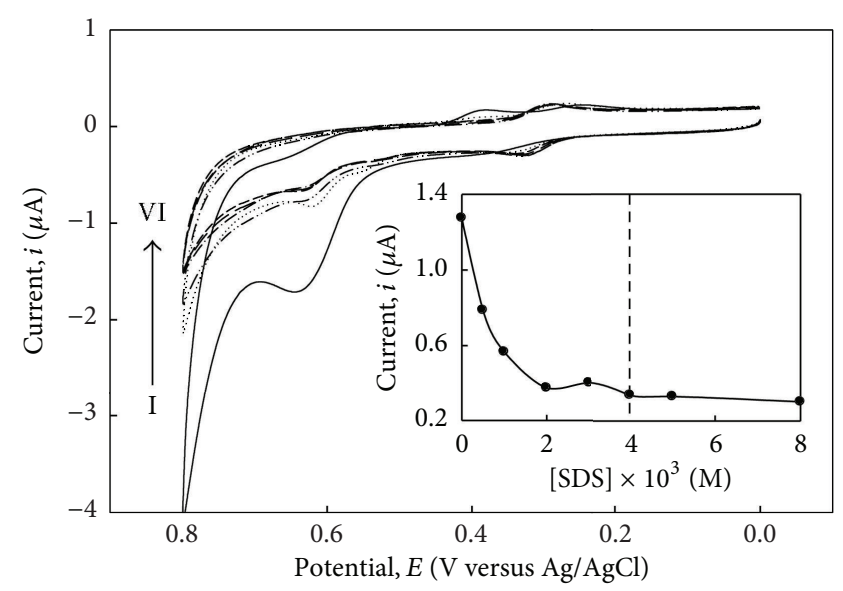

(b)

FIgURE 5: Cyclic voltammograms of $5 \times 10^{-4} \mathrm{M}$ MG in $0.10 \mathrm{M}$ aqueous solution of $\mathrm{KCl}$ at various concentrations of surfactants. (a) Cyclic voltammograms of MG in the presence of CTAB. Concentrations of CTAB (from I to VI): $0,0.25 \times 10^{-3}, 0.5 \times 10^{-3}, 1.0 \times 10^{-3}, 5 \times 10^{-3}$, $7.5 \times 10^{-3} \mathrm{M}$. (b) Cyclic voltammograms of MG in the presence of SDS. Concentrations of SDS (from I to VI): $0,1.0 \times 10^{-3}, 2.0 \times 10^{-3}, 3.0 \times 10^{-3}$, $4.0 \times 10^{-3}, 5.0 \times 10^{-3} \mathrm{M}$. The scan rate was $0.01 \mathrm{~V} \mathrm{~s}^{-1}$. Insets show plot of $i_{\mathrm{pa}}^{1}$ versus [surfactant].

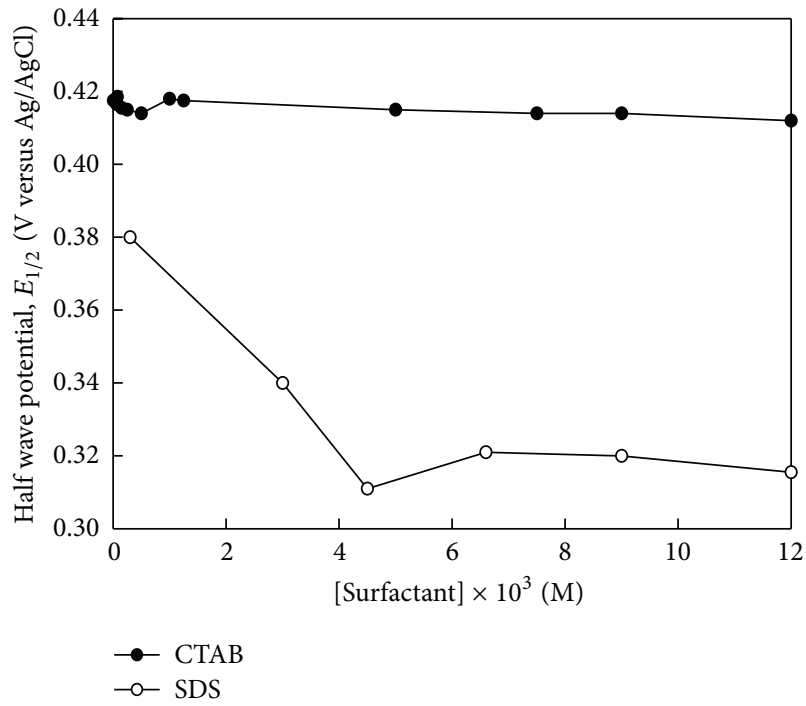

Figure 6: Half wave potential (versus $\mathrm{Ag} / \mathrm{AgCl}$ ) of the second cycle plotted against the concentration of $\mathrm{CTAB}$ and SDS for $\mathrm{TMBO} / \mathrm{TMB}$ redox couple in $0.10 \mathrm{M}$ aqueous solution of $\mathrm{KCl}$. The scan rate was $0.01 \mathrm{~V} \mathrm{~s}^{-1}$.

slight decrease at low concentrations of CTAB below its CMC value, which is indicative of the ease of the redox process in CTAB monomeric solutions.

The separation of peak potentials of TMBOx/TMB redox couple is higher than $0.030 \mathrm{~V}$ irrespective of the presence or absence of surfactants. As the separation of peak potentials is less than $0.059 / n \mathrm{~V}$ (here, $n=2$ ) cyclic voltammograms do not correspond to a reversible process. The ratio of the second anodic peak current of $\mathrm{O} 2$ and the cathodic peak current of $\mathrm{R} 1\left(i_{\mathrm{pa}}^{2} / i_{\mathrm{pc}}\right)$ is smaller than 1 , which indicates that the electrochemical reaction is complicated by some other processes like a following chemical reaction [38]. The ratio has been found to increase with increasing scan rates to support this conclusion.

3.4. Chemical Oxidation of $M G$ and Evidence for the Formation of TMBOx/TMB Redox Couple. $5.0 \times 10^{-4} \mathrm{M}$ MG was oxidized in $1.0 \mathrm{M} \mathrm{H}_{2} \mathrm{SO}_{4}$ with lead dioxide, which yielded a brown colored precipitate in the mixture. The precipitate underwent dissolution with added perchloric acid. The shapes of the cyclic voltammograms agree with those reported by Galus and Adams [18]. The chemical oxidation of MG leads to the formation of TMBOx, which is soluble in perchloric acid. The cyclic voltammetric behaviors of chemically oxidized MG solution, that is, TMBOx in aqueous solution of $\mathrm{KCl}$ at different $\mathrm{pH}$ ( $\mathrm{pH}$ was adjusted by addition of aqueous solution of $\mathrm{H}_{2} \mathrm{SO}_{4}$ or $\mathrm{NaOH}$ ) are shown in Figure 7. The oxidized MG gives a pair of well-defined redox peaks in the potential range of 0.80 to $0.30 \mathrm{~V}$ in acidic aqueous solution of $\mathrm{pH} 1.14$ with a reduction peak at $0.53 \mathrm{~V}$ and an oxidation peak at $0.56 \mathrm{~V}$, respectively. The peak potential shifts to less positive value of $0.46 \mathrm{~V}$ and $0.49 \mathrm{~V}$, respectively at $\mathrm{pH} 2.14$. In highly alkaline media of $\mathrm{pH} 10.70$, the cyclic voltammogram shows one anodic peak which is electrochemically irreversible.

Aqueous solution of $\mathrm{MG}$ has three absorption peaks in the range of $200-800 \mathrm{~nm}$ with absorption maximum at wavelength $617.5,424.5$, and $316.5 \mathrm{~nm}$, respectively. The absorbance at $617.5 \mathrm{~nm}$ is found to decrease abruptly with decreasing $\mathrm{pH}$ of the aqueous solution of MG. The UV-visible spectrum of chemically oxidized MG solution is different from that of MG aqueous solution (Figure 8). The TMBOx in acidic medium is yellowish in color, and at $\mathrm{pH} 1.70$ the spectrum showed two absorption peaks at 256.0 and $461.0 \mathrm{~nm}$. A new peak at $204.0 \mathrm{~nm}$ appeared in a highly acidic medium of $\mathrm{pH}<1.20$. Jiao et al. [39] reported that at $\mathrm{pH}$ $2.00,3,3^{\prime}, 5,5^{\prime}$-tetramethylbenzidine (another form of TMB) gives absorption peaks in the UV-visible region, respectively 


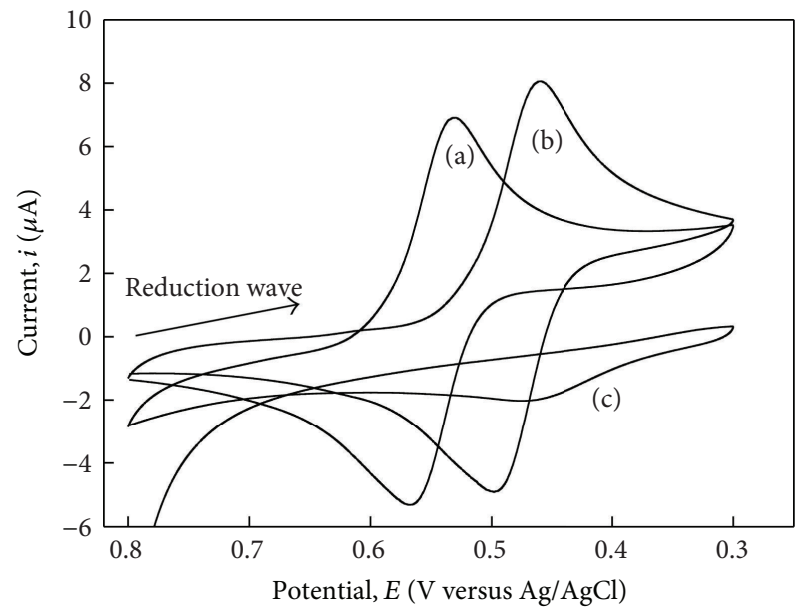

$\mathrm{pH}=$
(a) 1.14
(b) 2.40
(c) 10.71

Figure 7: Cyclic voltammograms of chemically oxidized MG (5.0 $\times$ $\left.10^{-4} \mathrm{M} \mathrm{MG}+2.9 \times 10^{-3} \mathrm{M} \mathrm{PbO}_{2}+\mathrm{H}_{2} \mathrm{SO}_{4}+\mathrm{HClO}_{4}\right)$ in aqueous solution of $\mathrm{KCl}$ at different $\mathrm{pH}$. The $\mathrm{pH}$ was adjusted by aqueous solution of $\mathrm{H}_{2} \mathrm{SO}_{4}$ or $\mathrm{NaOH}$. The scan rate was $0.01 \mathrm{~V} \mathrm{~s}^{-1}$.

at $204 \mathrm{~nm}$ and $253.0 \mathrm{~nm}$. Moreover, a new absorption peak at $452.0 \mathrm{~nm}$ appears due to the absorbance of the oxidative product of $3,3^{\prime}, 5,5^{\prime}$-tetramethylbenzidine. $3,3^{\prime}, 5,5^{\prime}$ tetramethylbenzidine belongs to biphenyl group with the similar structure of TMB. Therefore, it can be inferred that both TMB and TMBOx are produced from the chemical oxidation of MG. The differences in the absorption band arise due to the different position of alkyl substituent in benzidine ring and the effect of solvent polarity.

3.5. Diffusion, Electron Transfer Kinetics and Surface Reaction Rate of MG in the Absence and Presence of Surfactants. For an electrochemically irreversible diffusion-controlled system, the diffusion coefficient can be evaluated by using [40]

$$
i_{\mathrm{pa}}^{1}=\left(2.99 \times 10^{5}\right) n^{3 / 2}(\alpha)^{1 / 2} A c D_{\mathrm{app}}^{1 / 2} v^{1 / 2},
$$

where $i_{\mathrm{pa}}^{1}$ is the anodic peak current in amperes at $25^{\circ} \mathrm{C}, n$ is the number of electrons taking part in the electrochemical reaction, $\alpha$ is the electron transfer coefficient, $A$ is the geometric area of the electrode surface in $\mathrm{m}^{2}, D_{\text {app }}$ is the diffusion coefficient of electroactive species in $\mathrm{m}^{2} \mathrm{~s}^{-1}, v$ is the potential sweep rate in $\mathrm{V} \mathrm{s}^{-1}$, and $c$ is the concentration of the reactive species in the bulk of the solution in $\mathrm{mol} \mathrm{m}^{-3}$. The electron transfer coefficient $\alpha$, for an irreversible process can be calculated from [40]

$$
\left|E_{\mathrm{pa}}^{1}-E_{\mathrm{pa} / 2}^{1}\right|=\frac{47.7}{n \propto} \mathrm{mV}
$$

where $E_{\mathrm{pa}}^{1}$ and $E_{\mathrm{pa} / 2}^{1}$ are the anodic peak potential and the potential at which the current equals one half of the peak current, respectively. A linear relationship between, $i_{\mathrm{pa}}^{1}$ and

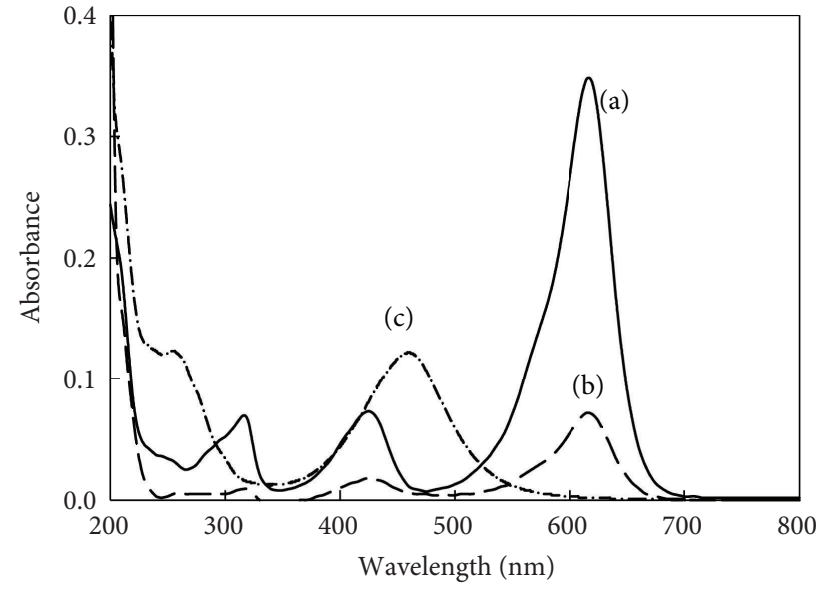

Figure 8: UV-visible spectra of (a) $2.0 \times 10^{-6} \mathrm{M} \mathrm{MG}$ in aqueous solution of $\mathrm{KCl}$ without $\mathrm{pH}$ adjustment; (b) $2.0 \times 10^{-6} \mathrm{M} \mathrm{MG}$ in aqueous solution of $\mathrm{KCl}$ at $\mathrm{pH} 1.70$, and (c) $5.0 \times 10^{-4} \mathrm{M} \mathrm{MG}$ chemically oxidized by $1.0 \mathrm{M} \mathrm{H}_{2} \mathrm{SO}_{4}+2.9 \times 10^{-3} \mathrm{M} \mathrm{PbO}_{2}+\mathrm{HClO}_{4}$ in aqueous solution of $\mathrm{KCl}$ at $\mathrm{pH} 1.70$.

$v^{1 / 2}$ is apparent (Figure 4(a)), and the apparent diffusion coefficient $\left(D_{\text {app }}\right)$ of MG is calculated from (1) as $4.8 \times 10^{-11}$ $\mathrm{m}^{2} \mathrm{~s}^{-1}$.

The study of kinetics of a reaction at an electrode surface is important for fundamental understanding of the heterogeneous electron transfer process. Since the oxidation process of MG is diffusion controlled, the surface reaction rate constant $\left(k_{s}\right)$ can be calculated from $[13,37]$

$$
E_{\mathrm{pa}}^{1}=E^{0 \prime}+\left\{0.780+0.5 \ln \left(\frac{n \alpha D_{\mathrm{app}} F v}{R T}\right)-\ln k_{s}\right\} \frac{R T}{n \alpha F},
$$

where, $E_{\mathrm{pa}}^{1}, E^{0 \prime}$, and $n$ are anodic peak potential, the formal potential, and number of electrons taking part in the rate determining step ( $=2$ in the present case), respectively, and $R, T, \alpha, D_{\text {app }}, F$, and $v$ stand for their usual meanings. A linear relationship holds for $E_{\mathrm{pa}}^{1}$ versus $\ln v$. The value of $k_{s}$ can be obtained from the intercept of the straight line if the values of $n, D_{\text {app }}$, and $E^{0 \prime}$ are known. The slope of $E_{\mathrm{pa}}^{1}$ versus $\ln v$ evaluated from data of Figure 4 (a) was $7.77 \times 10^{-3}$. The oxidation of MG is an electrochemically irreversible process to make the direct measurement of the accurate value of $E^{0 \prime}$ difficult. However, the value of $E^{0 \prime}$ could be obtained from the intercept of the $E_{\mathrm{pa}}^{1}$ versus $v$ plot on the ordinate by extrapolating the line to $v=0$ following the method described in the literature $[13,17]$. The parameters estimated are $E^{0 \prime}=0.63 \mathrm{~V}, \alpha=0.48$ and $k_{s}=2.76 \times 10^{-3} \mathrm{~s}^{-1}$.

The $D_{\text {app }}, \alpha$, and $k_{s}$ are also evaluated for the peak O1 in the presence of surfactants, CTAB, and SDS. Table 1 lists the values of $D_{\text {app }}, \alpha$, and $k_{s}$ for $5.0 \times 10^{-4} \mathrm{M} \mathrm{MG}$ in $0.10 \mathrm{M}$ aqueous solution of $\mathrm{KCl}$ in the presence of CTAB and SDS at various concentrations.

The results demonstrated that the electrochemical parameters of MG varied significantly with the addition of CTAB 
TABLE 1: $D_{\text {app }}, \alpha$, and $k_{s}$ of MG in the presence of surfactants CTAB and SDS.

\begin{tabular}{lcccc}
\hline Surfactants [Surfactant] $\times 10^{3}, \mathrm{M}$ & $\begin{array}{c}D_{\mathrm{app}} \times 10^{11}, \\
\mathrm{~m}^{2} \mathrm{~s}^{-1}\end{array}$ & $\alpha$ & $\begin{array}{c}k_{s} \times 10^{3}, \\
\mathrm{~s}^{-1}\end{array}$ \\
\hline 0.005 & 6.4 & 0.48 & 1.05 \\
& 0.15 & 7.2 & 0.47 & 1.63 \\
$\mathrm{CTAB}$ & 0.25 & 9.4 & 0.47 & 1.79 \\
& 0.75 & 10.1 & 0.47 & 1.82 \\
& 1.00 & 9.8 & 0.47 & 1.88 \\
& 1.25 & 12.6 & 0.47 & 2.19 \\
& 5.00 & 15.1 & 0.47 & 2.29 \\
& 7.50 & 12.1 & 0.47 & 2.30 \\
\hline \multirow{4}{*}{ SDS } & 0.50 & 2.6 & 0.40 & 1.22 \\
& 1.00 & 2.0 & 0.49 & 0.99 \\
& 2.00 & 0.8 & 0.47 & 0.88 \\
& 3.00 & 0.6 & 0.47 & 0.60 \\
& 4.00 & 0.4 & 0.47 & 0.41 \\
& 5.00 & 0.3 & 0.47 & 0.20 \\
\hline
\end{tabular}

and SDS. The addition of CTAB in aqueous solution increases the $D_{\text {app }}$ of MG up to $1.00 \times 10^{-3} \mathrm{M}$ of CTAB. Above $1.00 \times$ $10^{-3} \mathrm{M}$ of CTAB, the $D_{\text {app }}$ increases slightly; however, the value remains constant over the wide range of [CTAB]. The $D_{\text {app }}$ and $k_{s}$ of MG decrease appreciably with increasing SDS concentration, and in this case $\alpha$ slightly varied at lower concentrations of SDS. The possibility of MG incorporation in $\mathrm{CTAB}$ micelle can only be attributed to hydrophobic interactions. As the concentration of CTAB increases above the CMC, the fixed amount of MG is incorporated in micellar core and the micelle is then less diffusive towards electrode surface. On the other hand, the presence of positive charge on the amino group of $\mathrm{MG}$ and its hydrophobic nature enhances the aggregation of MG with SDS. The strength of interaction and binding between MG and SDS can partially affect the diffusion of MG in solution. Moreover, the formation of an electrochemically inactive complex of MG with SDS can lower the concentration of free MG in the system to result in the decrease of the peak current and hence the $D_{\text {app }}$. The $k_{s}$ value has been found to decrease with increasing SDS, while an opposite trend is observed for CTAB. Zhu and $\mathrm{Li}$ also [41] correlated such change in electrochemical parameters with formation of electroactive or electrochemically inactive complexes. The oxidation of hydrated MG is a diffusion-controlled electrochemically irreversible process and depends on the various electrochemical parameters determined by specific interactions and solubilization behavior of the media, not merely on adsorption at the electrode interface.

\section{Conclusions}

The micellization properties of surfactants in aqueous solution have profound influence on the electrochemical behavior of MG and the shapes of the cyclic voltammograms that depend fairly on the concentration of the ionic surfactants, CTAB, and SDS. The electrochemical responses of MG at concentrations below and above the CMC of surfactants are distinctly different. A sharp decrease in peak current for MG in aqueous SDS solution indicates a strong interaction of MG with the surfactant while a slight increase is apparent in aqueous CTAB solution. The electrochemical oxidation of hydrated MG has been characterized as an electrochemically irreversible diffusion-controlled process. The apparent diffusion coefficient and the surface reaction rate constant increase with increase in CTAB concentration, but an opposite trend is observed for SDS.

\section{Conflict of Interests}

The authors declare that there is no conflict of interests regarding the publication of this paper.

\section{Acknowledgment}

The authors gratefully acknowledge financial support for a subproject (CP-231) from the Higher Education Quality Enhancement Project of the University Grants Commission of Bangladesh financed by the World Bank and the Government of Bangladesh.

\section{References}

[1] S. J. Culp and F. A. Beland, "Malachite green: a toxicological review," International Journal of Toxicology, vol. 15, no. 3, pp. 219-238, 1996.

[2] P. Ngamukot, T. Charoenraks, O. Chailapakul, S. Motomizu, and S. Chuanuwatanakul, "Cost-effective flow cell for the determination of malachite green and leucomalachite green at a boron-doped diamond thin-film electrode," Analytical Sciences, vol. 22, no. 1, pp. 111-116, 2006.

[3] K. K. Karukstis and A. V. Gulledge, "Analysis of the solvatochromic behavior of the disubstituted triphenylmethane dye brilliant green," Analytical Chemistry, vol. 70, no. 19, pp. 42124217, 1998.

[4] X. Niu, W. Zhang, N. Zhao, and W. Sun, "Voltammetric determination of heparin based on its interaction with malachite green," Bulletin of the Chemical Society of Ethiopia, vol. 22, no. 2, pp. 162-172, 2008.

[5] K. Qu, X. Zhang, Z. Lv et al., "Simultaneous detection of diethylstilbestrol and malachite green using conductive carbon black paste electrode," International Journal of Electrochemical Science, vol. 7, no. 3, pp. 1827-1839, 2012.

[6] R. M. Uda and K. Kimura, "Microscopic location of photosensitive malachite Green surfactant in mixed micelle and its photoinduced enhancement of solubilizing power," Colloid and Polymer Science, vol. 285, no. 6, pp. 699-704, 2007.

[7] R. C. Kaye and H. I. Stonehill, "The polarographic reduction of crystal-violet, brilliant-green, malachite-green, and auramine," Journal of the Chemical Society, vol. 618, pp. 3231-3239, 1952.

[8] J. Mata, D. Varade, and P. Bahadur, "Aggregation behavior of quaternary salt based cationic surfactants," Thermochimica Acta, vol. 428, no. 1-2, pp. 147-155, 2005. 
[9] M. N. Khan and A. Sarwar, "Study of dye-surfactant interaction: aggregation and dissolution of yellowish in $\mathrm{N}$-dodecyl pyridinum chloride," Fluid Phase Equilibria, vol. 239, no. 2, pp. 166$171,2006$.

[10] S. M. Chen, J. Y. Chen, and R. Thangamuthu, "Electrochemical preparation of poly(malachite green) film modified Nafioncoated glassy carbon electrode and its electrocatalytic behavior towards NADH, dopamine and ascorbic acid," Electroanalysis, vol. 19, no. 14, pp. 1531-1538, 2007.

[11] L. Antonov, G. Gergov, V. Petrov, M. Kubista, and J. Nygren, "UV-Vis spectroscopic and chemometric study on the aggregation of ionic dyes in water," Talanta, vol. 49, no. 1, pp. 99-106, 1999.

[12] A. M. R. Kabir and M. A. B. H. Susan, "Kinetics of the alkaline hydrolysis of crystal violet $\mathrm{n}$ aqueous solution influenced by anionic surfactants," Journal of Saudi Chemical Society, vol. 12, no. 4, pp. 543-554, 2008.

[13] X. Hu, K. Jiao, W. Sun, and J.-Y. You, "Electrochemical and spectroscopic studies on the interaction of malachite green with DNA and its application," Electroanalysis, vol. 18, no. 6, pp. 613620, 2006.

[14] N. S. Kobotaeva, E. E. Sirotkina, and E. V. Mikubaeva, "Electrochemical oxidation of tritane dyes," Russian Journal of Electrochemistry, vol. 42, no. 3, pp. 268-271, 2006.

[15] V. V. Perekotii, Z. A. Temerdashev, T. G. Tsyupko, and E. A. Palenaya, "Electrochemical behavior of crystal violet on glassy carbon electrodes," Journal of Analytical Chemistry, vol. 57, no. 5, pp. 448-451, 2002.

[16] J.-P. Song, Y.-J. Guo, S.-M. Shuang, and C. Dong, "Study on the inclusion interaction of ethyl violet with cyclodextrins by MWNTs/Nafion modified glassy carbon electrode," Journal of Inclusion Phenomena and Macrocyclic Chemistry, vol. 68, no. 34, pp. 467-473, 2010.

[17] B. Xu, K. Jiao, W. Sun, and X. Zhang, "Recognition and determination of DNA using victoria blue $b$ as electrochemical probe," International Journal of Electrochemical Science, vol. 2, no. 5, pp. 406-417, 2007.

[18] Z. Galus and R. N. Adams, "The anodic oxidation of triphenylmethane dyes," Journal of the American Chemical Society, vol. 86, no. 9, pp. 1666-1671, 1964.

[19] D. A. Hall, M. Sakuma, and P. J. Elving, "Voltammetric oxidation of triphenylmethane dyes at platinum in liquid sulphur dioxide," Electrochimica Acta, vol. 11, no. 3, pp. 337-350, 1966.

[20] M. M. Rahman, M. Y. A. Mollah, M. M. Rahman, and M. A. B. H. Susan, "Electrochemical behavior of malachite green on a glassy carbon electrode: a cyclic voltammetric study," Journal of Bangladesh Chemical Society, vol. 24, no. 1, pp. 25-36, 2011.

[21] T. Saji, K. Hoshino, and S. Aoyagui, "Reversible formation and disruption of micelles by control of the redox state of the head group," Journal of the American Chemical Society, vol. 107, no. 24, pp. 6865-6868, 1985.

[22] Y. Takeoka, T. Aoki, K. Sanui, N. Ogata, and M. Watanabe, "Electrochemical studies of a redox-active surfactant. Correlation between electrochemical responses and dissolved states," Langmuir, vol. 12, no. 2, pp. 487-493, 1996.

[23] M. A. B. H. Susan, K. Tani, and M. Watanabe, "Surface activity and redox behavior of nonionic surfactants containing an anthraquinone group as the redox-active site," Colloid and Polymer Science, vol. 277, no. 12, pp. 1125-1133, 1999.

[24] M. A. B. H. Susan, M. Begum, Y. Takeoka, and M. Watanabe, "Effect of $\mathrm{pH}$ and the extent of micellization on the redox behavior of non-ionic surfactants containing an anthraquinone group," Journal of Electroanalytical Chemistry, vol. 481, no. 2, pp. 192-199, 2000.

[25] M. A. B. H. Susan, M. Begum, Y. Takeoka, and M. Watanabe, "Study of the correlation of the cyclic voltammetric responses of a nonionic surfactant containing an anthraquinone group with the dissolved states," Langmuir, vol. 16, no. 7, pp. 3509-3516, 2000.

[26] M. A. Haque, M. M. Rahman, and M. A. B. H. Susan, "Aqueous electrochemistry of anthraquinone and its correlation with the dissolved states of a cationic surfactant," Journal of Solution Chemistry, vol. 40, no. 5, pp. 861-875, 2011.

[27] M. A. Haque, M. M. Rahman, and M. A. B. H. Susan, "Electrochemical behavior of anthraquinone in reverse micelles and microemulsions of cetyltrimethylammonium bromide," Journal of Solution Chemistry, vol. 41, no. 3, pp. 447-457, 2012.

[28] I. Mahmud, A. J. F. Samed, M. A. Haque, and M. A. B. H. Susan, "Electrochemical behavior of anthraquinone in aqueous solution in presence of a non-ionic surfactant," Journal of Saudi Chemical Society, vol. 15, no. 3, pp. 203-208, 2011.

[29] A. Pedraza, M. D. Sicilia, S. Rubio, and D. Pérez-Bendito, "Determination of aromatic hydrotropic drugs in pharmaceutical preparations by the surfactant-binding degree method," Analyst, vol. 130, no. 7, pp. 1102-1107, 2005.

[30] B. Gohain, B. Boruah, P. M. Saikia, and R. K. Dutta, "Premicellar and micelle formation behavior of aqueous anionic surfactants in the presence of triphenylmethane dyes: protonation of dye in ion pair micelles," Journal of Physical Organic Chemistry, vol. 23, no. 3, pp. 211-219, 2010.

[31] W. Huang, C. Yang, W. Qu, and S. Zhang, "Voltammetric determination of malachite green in fish samples based on the enhancement effect of anionic surfactant," Russian Journal of Electrochemistry, vol. 44, no. 8, pp. 946-951, 2008.

[32] L. Liu, F. Zhao, F. Xiao, and B. Zeng, "Improved voltammetric response of malachite green at a multi-walled carbon nanotubes coated glassy carbon electrode in the presence of surfactant," International Journal of Electrochemical Science, vol. 4, no. 4, pp. 525-534, 2009.

[33] K. Yamamoto and S. Motomizu, "Liquid-liquid distribution of ion-associates of acidic dyes with quaternary ammonium counter-ions," Talanta, vol. 38, no. 5, pp. 477-482, 1991.

[34] M. Mukhopadhyay, C. Sen Varma, and B. B. Bhowmik, "Photoinduced electron transfer in surfactant solutions containing thionine dye," Colloid and Polymer Science, vol. 268, no. 5, pp. 447-451, 1990.

[35] W. Biedermann and A. Datyner, "The interaction of nonionic dyestuffs with sodium dodecyl sulfate and its correlation with lipophilic parameters," Journal of Colloid and Interface Science, vol. 82, no. 2, pp. 276-285, 1981.

[36] Z. Galus and R. N. Adams, "Anodic oxidation studies of N,Ndimethylaniline. II. Stationary and rotated disk studies at inert electrodes," Journal of the American Chemical Society, vol. 84, no. 11, pp. 2061-2065, 1962.

[37] A. J. Bard and L. R. Faulkner, Electrochemical Methods: Fundamental and Applications, John Wiley \& Sons, Beijing, China, 2nd edition, 2004.

[38] R. S. Nicholson and I. Shain, "Theory of stationary electrode polarography single scan and cyclic methods applied to reversible, irreversible, and kinetic systems," Analytical Chemistry, vol. 36, no. 4, pp. 706-723, 1964.

[39] K. Jiao, T. Yang, and S. Niu, "Thin-layer spectroelectrochemical study of $3,3^{\prime}, 5,5^{\prime}$-tetramethylbenzidine at $\mathrm{SnO}_{2}$ :F film optically 
transparent electrode," Science in China B, vol. 47, no. 4, pp. 267275, 2004.

[40] C. M. A. Brett and A. M. O. Brett, Electrochemistry, Principles, Methods, and Applications, Oxford University Press, NewYork, NY, USA, 1994.

[41] Z. Zhu and N.-Q. Li, "Electrochemical studies of 9,10-anthraquinone interacting with hemoglobin and determination of hemoglobin," Mikrochimica Acta, vol. 130, no. 4, pp. 301-308, 1999. 


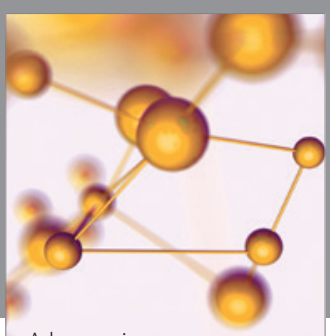

Physical Chemistry
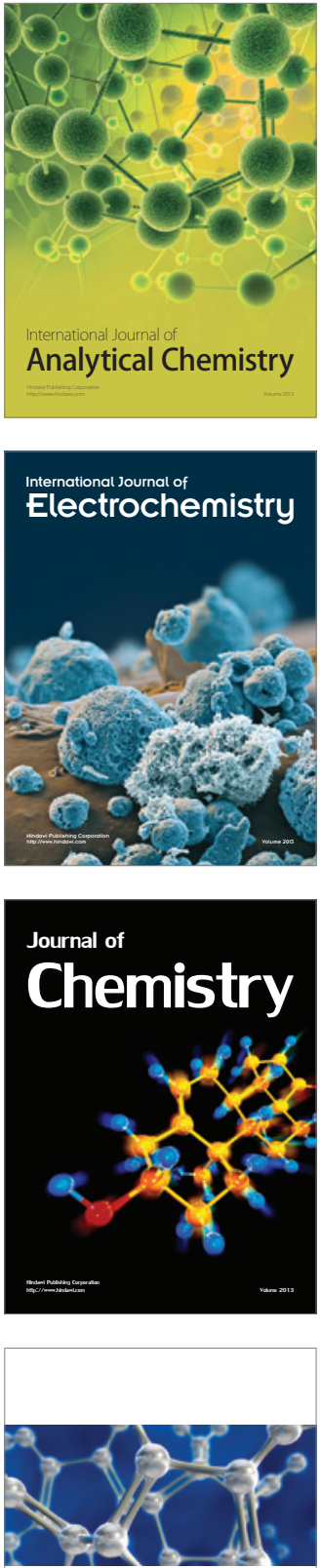

ISRN

Inorganic Chemistry

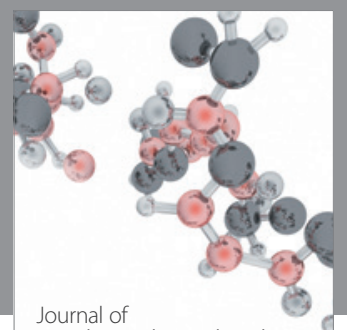

Analytical Methods in Chemistry

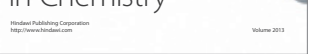

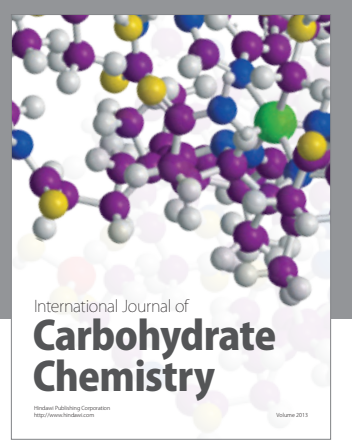
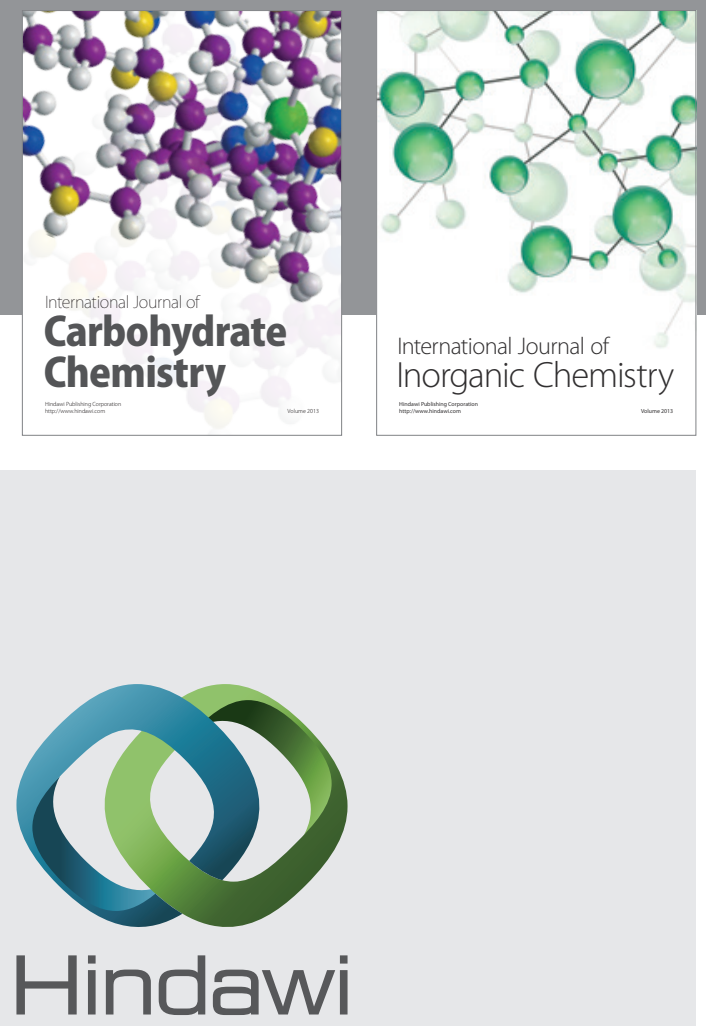

Submit your manuscripts at http://www.hindawi.com
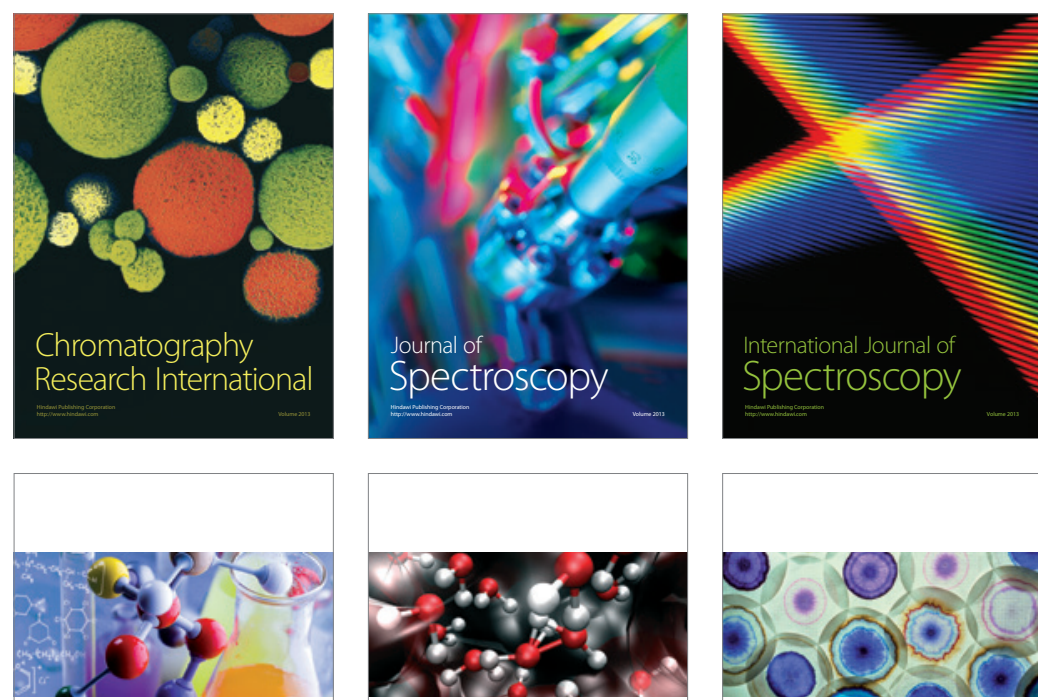

ISRN

ISRN

Organic Chemistry

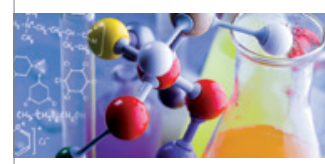

Physical Chemistry

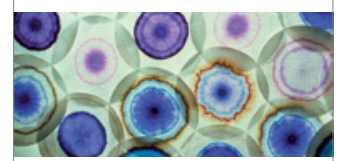

ISRN

Chromatography

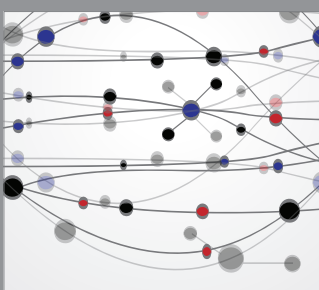

The Scientific World Journal
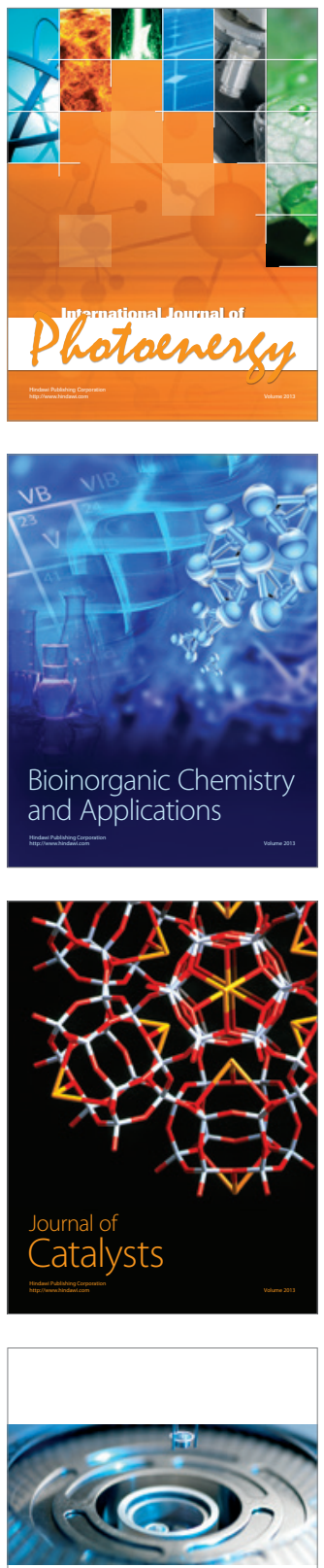

ISRN

Analytical

Chemistry 


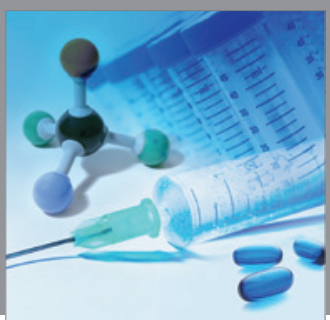

International Journal of

Medicinal Chemistry

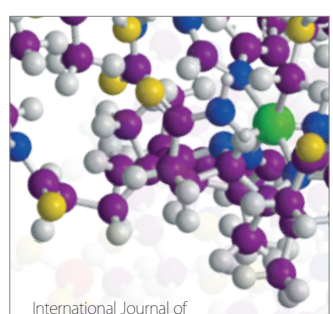

Carbohydrate Chemistry

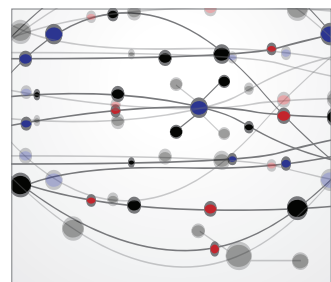

The Scientific World Journal
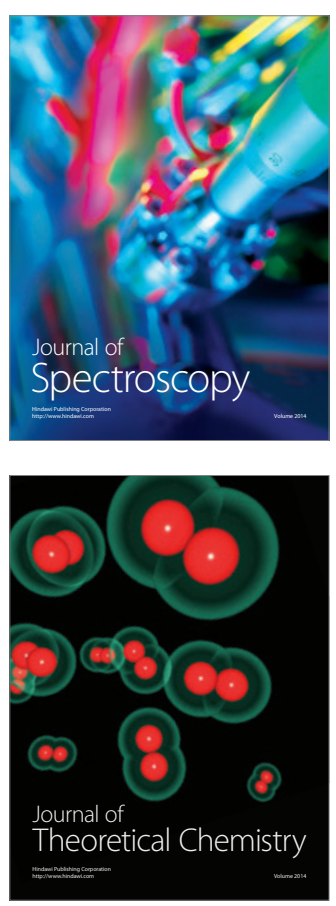
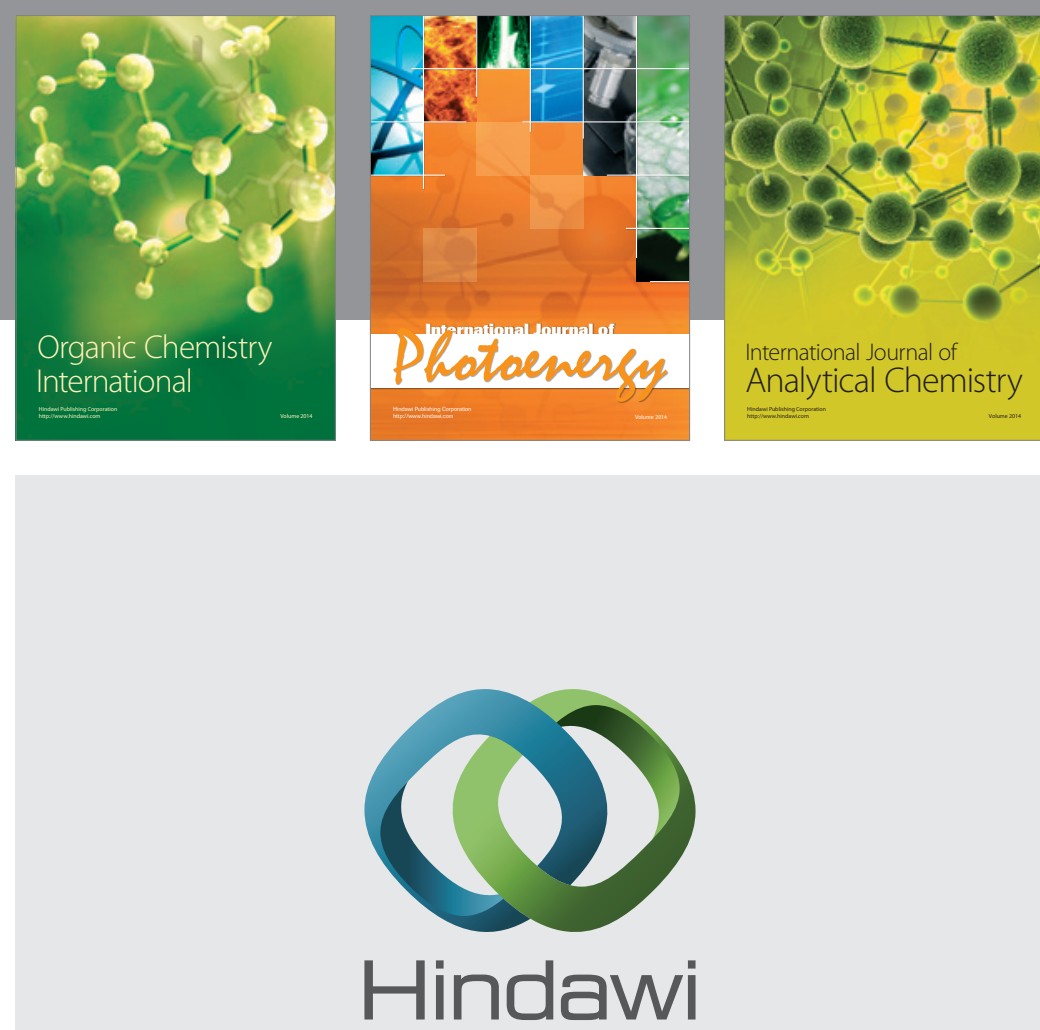

Submit your manuscripts at

http://www.hindawi.com
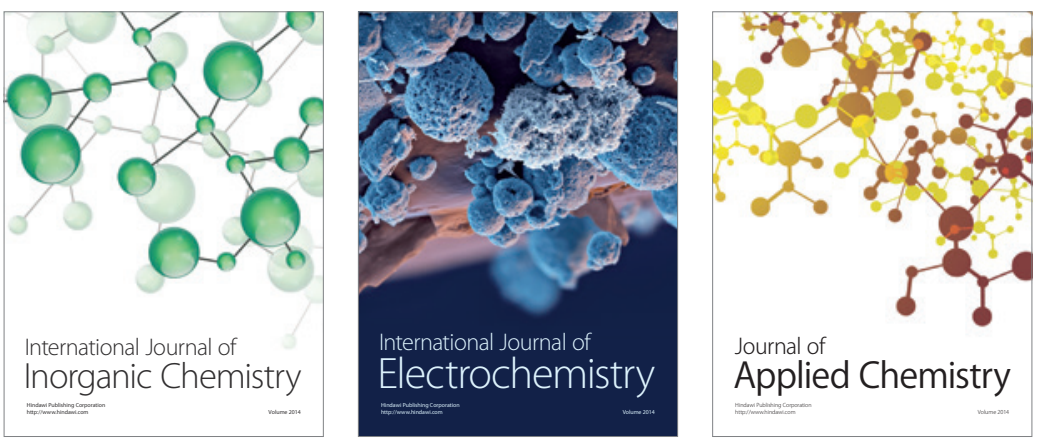

Journal of

Applied Chemistry
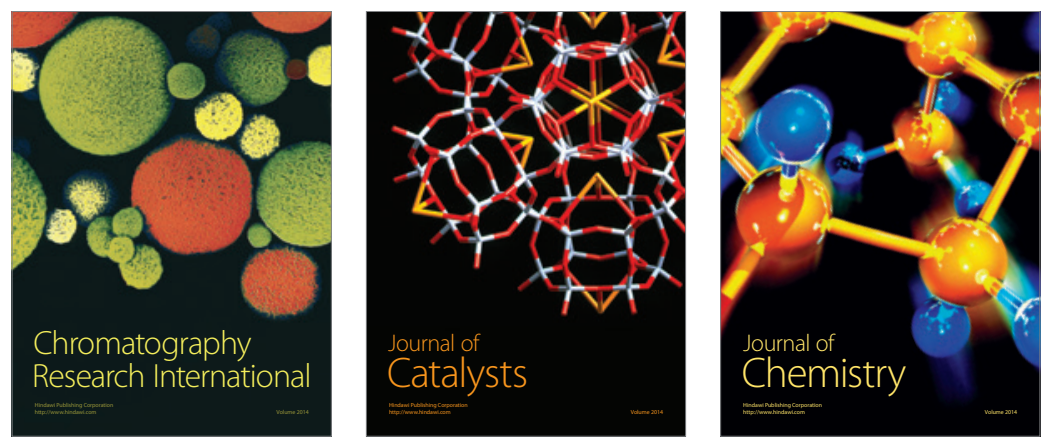
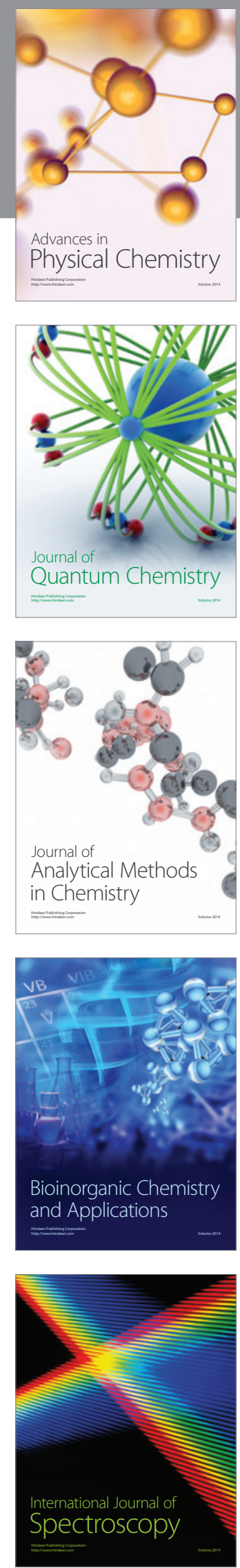